Article

\title{
Nusselt Number Correlation for Vertical Tubes with Inverted Triangular Fins under Natural Convection
}

\author{
Byeong Dong Kang, Hyun Jung Kim and Dong-Kwon Kim * \\ Department of Mechanical Engineering, Ajou University, Suwon 443-749, Korea; ssalpond@ajou.ac.kr (B.D.K.); \\ hyunkim@ajou.ac.kr (H.J.K.) \\ * Correspondence: dkim@ajou.ac.kr; Tel.: +82-31-219-3660
}

Received: 12 July 2017; Accepted: 1 August 2017; Published: 10 August 2017

\begin{abstract}
Vertical tubes with inverted triangular fins under natural convection are investigated experimentally. The thermal resistances of tubes with inverted triangular fins are measured for various fin numbers, fin heights, and heat inputs. A Nusselt number correlation that best predicts the measured thermal resistances is proposed. The proposed correlation is applicable to the following conditions: Rayleigh numbers of 1000-125,000, fin height to fin length ratios of 0.2-0.6, and fin numbers of 9-72. Finally, a contour map of the thermal resistances calculated from the proposed correlation for various fin thicknesses and fin numbers is presented. The contour map shows that there exist optimal values of the fin thickness and fin number at which the thermal resistance of the inverted-triangular-finned tube is minimized. Therefore, the proposed correlation enables a search for the optimal dimensions and has potential to be used in the designing of inverted-triangular-finned tubes of various cooling devices.
\end{abstract}

Keywords: free convection; inverted triangular fin; vertical-finned tube

\section{Introduction}

Owing to the recent advances in energy conversion systems, heat dissipation from these systems increases rapidly, and cooling devices for these systems become indispensable components to ensure good performance and high reliability. For example, with recent advances in energy-efficient and reliable light-emitting diodes (LEDs), LED lighting is increasingly being employed in various lighting systems, such as household lamps and automotive lamps [1]. When electrical power is converted to light in the LED lighting, $60-80 \%$ of the electrical power dissipates as heat [2]. If the luminous efficacy, i.e., the ratio of luminous power to electrical power, is $100 \mathrm{~lm} / \mathrm{W}$, a $2400 \mathrm{~lm}$ LED lighting system requires an electrical power of $24 \mathrm{~W}$ and generates heat of 14-19 W. Ineffective dissipation of this generated heat may cause a significant decrease in the luminous efficacy and the time to failure owing to degradation of the LED material and the transparent package [3-7]. Therefore, a cooling device of LED lighting is an indispensable component to ensure good performance and high reliability of the lighting. Among the various cooling devices that have been proposed, thus, far $[8,9]$, the most commonly used ones are heat sinks under natural convection. This is because the cooling device is required to be reliable, silent, energy-efficient, and cost-effective. Therefore, as presented in Table 1, many previous researchers investigated natural convection from flat and curved surfaces [10-13]. Furthermore, many previous researchers focused on natural convection from finned surfaces [14-17], because the finned surfaces have better thermal performances compared to the bare surfaces. Many previous studies have investigated radial heat sinks under natural convection. A radial heat sink has a thin disk and fins that are attached on top of the base and are arranged radially (Figure 1). Yu et al. conducted a comprehensive numerical and experimental investigation of natural convection from a plate-fin heat sink [18]. They investigated the effects of the fin number, fin height, 
fin length, and heat flux on the thermal resistance and found the correlation for predicting the Nusselt number. Costa and Lopes also numerically studied natural convection from the plate-fin heat sink; they proposed a procedure for finding the geometrical configuration of the heat sink that minimizes the mass when the required thermal performance is given [19]. Yu et al. numerically investigated the thermal performance of a plate-fin heat sink with different fin lengths; they showed that the heat sink with long and intermediate fins exhibited superior thermal performance to those with only long fins and those with long, intermediate, and short fins [20]. Jang et al. numerically optimized the thermal performance and mass of a pin-fin heat sink; they found that the pin-fin heat sink can reduce the mass by $30 \%$ compared to the plate-fin heat sink, without any loss of thermal performance [21]. Jang et al. numerically investigated the thermal performance of a pin-fin heat sink with different fin heights; they showed that the thermal performance can be improved by employing taller pin-fins in the outer region [22]. Park et al. numerically optimized the thermal performance of a heat sink with a staggered array of pin-fins; they found that the staggered pin-fin heat sink has a $10 \%$ higher optimal performance than the in-line pin-fin heat sink at a given mass [23]. The effects of a hollow cylinder and a chimney attached to a heat sink on the thermal performance were also investigated in different studies $[24,25]$. These studies revealed that the thermal performance of the heat sink improved through installation of the hollow cylinder or the chimney because of the increase in the flow rate through the heat sink.

Table 1. Summary of investigations on natural convection.

\begin{tabular}{ccc}
\hline Reference & Geomertry & Authors \\
\hline$[10]$ & Vertical plates & Churchill and Chu \\
{$[11]$} & Horizontal plates & Goldstein et al. \\
{$[12]$} & Vertical cylinders & Minkowycz and Sparrow \\
{$[13]$} & Horizontal cylinders & Churchill and Chu \\
{$[14]$} & Rectangular-finned horizontal plates & Harahap and McManus \\
{$[15]$} & Rectangular-finned vertical plates & Welling and Wooldridge \\
{$[16]$} & Square-finned horizontal tubes & Sparrow and Bahrami \\
{$[17]$} & Annular-finned horizontal tubes & Yildiz and Yüncü \\
\hline
\end{tabular}

On the other hand, many previous studies investigated the use of radially-finned tubes under natural convection. A radially-finned tube has a thick tubular base and fins that are attached radially on the side of the base (Figure 2). An et al. conducted an experimental investigation of natural convection from a plate-finned tube (Figure 2a) [26]; they investigated the effects of the fin number, fin height, and heat flux on the thermal resistance and found the correlation for predicting the Nusselt number. Park et al. experimentally investigated the thermal performance of a branched finned tube [27]; they found that it has a $36 \%$ higher optimal performance than the plate-finned tube. Jang et al. numerically investigated the effects of cross-cuts on the thermal performance of a finned tube (Figure $2 b$ ); they showed that the orientation dependence of the thermal performance of the finned tube with cross-cuts is smaller than that of the plate-finned tube [28]. Presently, triangular-finned tubes are being widely used to cool retrofit LED bulbs (Figure 3). The orientation of these bulbs is not fixed, and they can be installed in the inverted orientation for some uplights in some cases. As a result, triangular-finned tubes can be used in the inverted orientation (Figure 3b). Heat sinks under natural convection generally show the highest thermal resistance when they are inverted [25]. Therefore, it is important to obtain the thermal resistances of inverted-triangular-finned tubes quantitatively. However, to the best of our knowledge, natural convection from these inverted-triangular-finned tubes has not yet been extensively investigated experimentally.

The present study experimentally investigates vertical tubes with inverted triangular fins under free convection by extending our recent study on a tube with normal triangular fins [29]. The thermal resistances of tubes with inverted triangular fins are measured for various fin numbers, fin heights, and heat inputs. A Nusselt number correlation that best predicts the measured thermal resistances 
is proposed. Finally, a contour map of the thermal resistances calculated from the proposed correlation for various fin thicknesses and fin numbers is presented. From the contour map, the minimal thermal resistance of the vertical tube with inverted triangular fins and the conditions under which the thermal resistance is minimized are found.

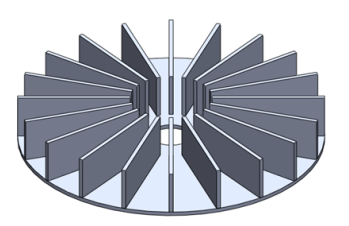

Figure 1. Schematic drawing of radial heat sink.

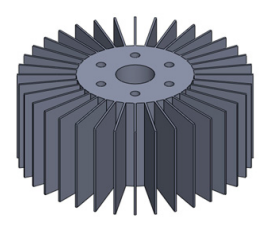

(a)

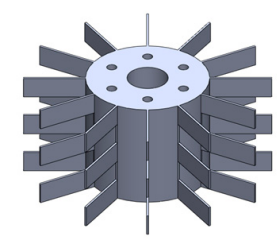

(b)

Figure 2. Radially-finned tube: (a) plate-finned tube; (b) plate-finned tube with cross-cuts.

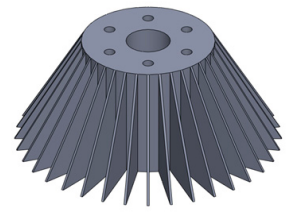

(a)

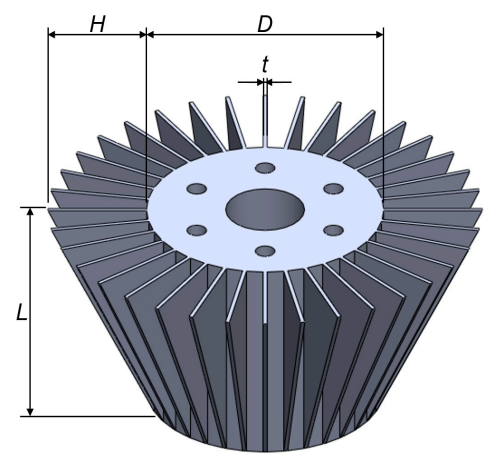

(b)

Figure 3. Schematic drawing of tube with triangular fins: (a) normal vertical orientation; (b) inverted orientation.

\section{Experimental Investigation}

The thermal resistances of tubes with inverted triangular fins, whose schematic diagram is shown in Figure 3b, were measured for various heat inputs $q$, fin heights $H$, and fin numbers $N$. The sizes of the tested finned tubes are tabulated in Table 2. As shown in the table, 12 different heat sinks with various fin heights and fin numbers were chosen. The finned tubes were composed of tubular bases and triangular fins, and they were constructed by interference fitting of the bases and fins. The bases were made of 6061 aluminum alloy, whose conductivity is $167 \mathrm{~W} / \mathrm{m} \cdot{ }^{\circ} \mathrm{C}$, and the fins were made of 5052 aluminum alloy, whose conductivity is $138 \mathrm{~W} / \mathrm{m} \cdot{ }^{\circ} \mathrm{C}$. The finned tube was sandwiched between Teflon blocks for supporting and insulating its top and bottom sides (Figure 4a,b). Then, $0.5-15.5 \mathrm{~W}$ of heat was applied to the finned tube by using a cartridge heater, which was mounted inside the finned tube (Figure 4c). This cartridge heater was operated by applying an electrical potential from a power supply (E3633A, Agilent Technologies, Santa Clara, CA, USA). The base temperatures were measured using four T-type thermocouples attached on the base. These thermocouples were connected to a data acquisition unit (34970A DAQ, Agilent Technologies) for converting temperature-dependent voltages obtained from the thermocouples to temperatures. The surrounding temperatures were also measured. 
The entire experimental setup was isolated in a quiescent space (the room was closed before the experiment, people were blocked from entering the room during the experiment, and the temperature of the room was $19 \pm 2{ }^{\circ} \mathrm{C}$. The air velocity was measured by using a hot wire anemometer (VT50, Kimo Instruments, Edenbridge, UK), and was less than $0.05 \mathrm{~m} / \mathrm{s}$.) The temperatures were measured only when the temperature variation in 3 min was smaller than $0.2{ }^{\circ} \mathrm{C}$.
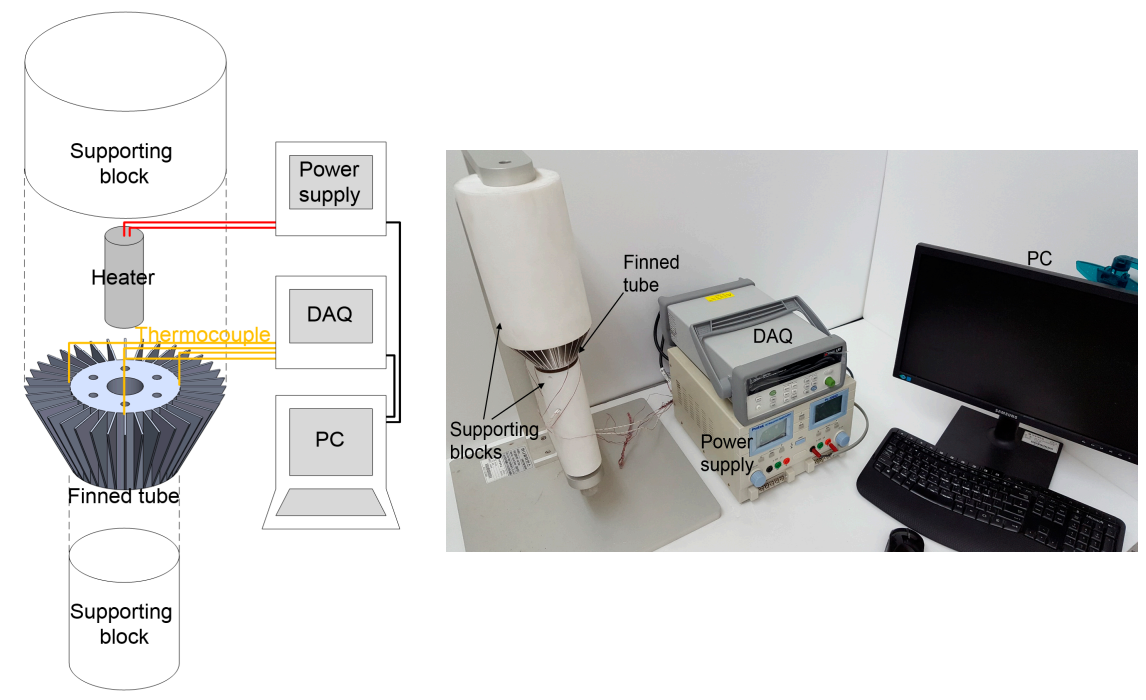

(a)

(b)

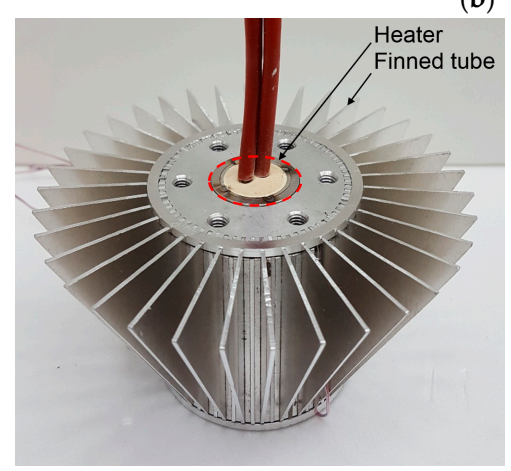

(c)

Figure 4. Experimental apparatus: (a) schematic drawing of experimental apparatus; (b) photograph of experimental apparatus; (c) photograph of inverted-triangular-finned tube.

Table 2. Dimensions of inverted-triangular-finned tubes.

\begin{tabular}{|c|c|c|c|c|}
\hline$D$ & $L$ & $t$ & $H$ & $N$ \\
\hline & & & $1.0 \mathrm{~cm}$ & $\begin{array}{c}9 \\
12 \\
18 \\
36 \\
72\end{array}$ \\
\hline $6.0 \mathrm{~cm}$ & $5.0 \mathrm{~cm}$ & $1.0 \mathrm{~mm}$ & $2.0 \mathrm{~cm}$ & $\begin{array}{c}9 \\
12 \\
18 \\
36 \\
72\end{array}$ \\
\hline & & & $3.0 \mathrm{~cm}$ & $\begin{array}{c}9 \\
12 \\
18 \\
36 \\
72\end{array}$ \\
\hline
\end{tabular}




\section{Results and Discussion}

The differences between the tube base temperatures and the ambient temperatures $(\Delta T)$ for various fin heights $(H)$, fin numbers $(N)$, and heat inputs $(q)$ were measured, as shown in Figure 5 and Table 3. Then, from the temperature differences, the thermal resistances of the inverted-triangular-finned tubes were obtained, as shown in Figure 6 and Table 3. The thermal resistance $R$ is defined as the temperature difference per unit heat input, and it is expressed as:

$$
R \equiv \Delta T / q
$$

As shown in Figure 6, the thermal resistance of the inverted-triangular-finned tube is minimized when the fin height is $0.03 \mathrm{~m}$ and the fin number is 36 . In the case of the normal vertical orientation investigated in a previous work [29], the thermal resistance is also minimized at the same fin height and fin number. Therefore, regardless of the orientation, the finned tube with the fin height of $0.03 \mathrm{~m}$ and fin number of 36 has the lowest thermal resistance among the 12 examined finned tubes.

The thermal resistance $R$ is closely related to the fin efficiency $\eta$, the heat transfer coefficient $h$, the fin surface area $A_{f}$, the unfinned surface area $A_{b}$, and the effective surface area $A_{\text {eff. }}$ The thermal resistance satisfies:

$$
R=1 /\left(h A_{e f f}\right)=1 /\left(h\left(A_{b}+\eta N A_{f}\right)\right)
$$

where:

$$
\begin{gathered}
A_{b}=\pi L D-t L N, \\
A_{f}=(t+L) H+\sqrt{L^{2}+H^{2}} t, \\
h=N u_{L} k_{f} / L, \\
\eta=2\left(\sqrt{\frac{2 h t}{k_{s}}} \frac{H}{t}\right)^{-1} I_{1}\left(\sqrt{\frac{2 h t}{k_{s}}} \frac{H}{t}\right)\left(I_{0}\left(\sqrt{\frac{2 h t}{k_{s}}} \frac{H}{t}\right)\right)^{-1} .
\end{gathered}
$$

Here, $k_{s}$ and $k_{f}$ are the solid thermal conductivity and fluid thermal conductivity, respectively. The Nusselt numbers $N u_{L}$ in Equation (5) can be obtained from the calculated thermal resistances by using Equations (2)-(6), and they are tabulated in Table 3.

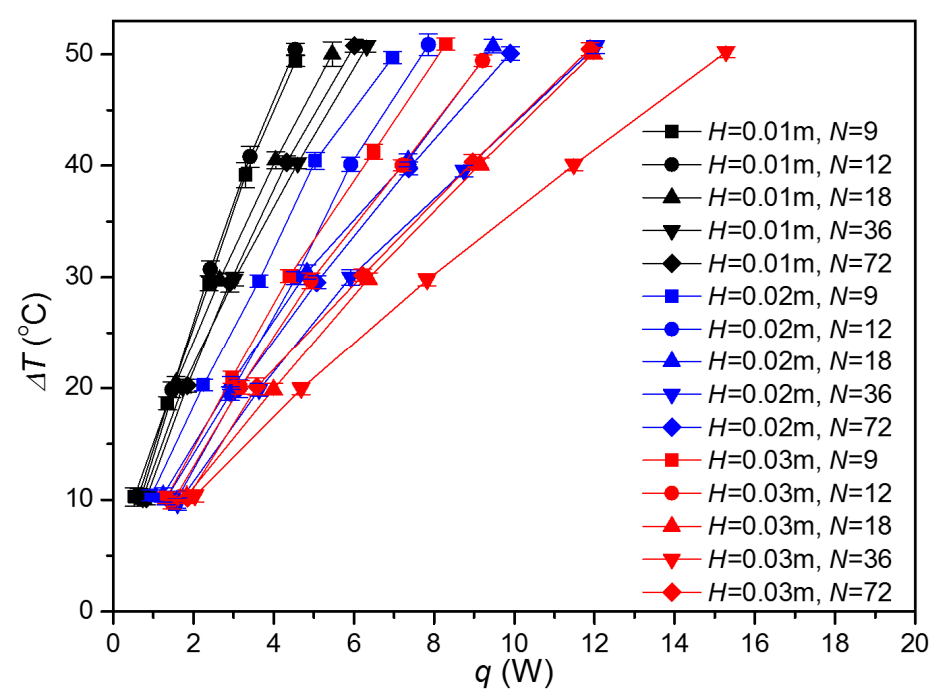

Figure 5. Measured temperature differences. 
Table 3. Measurement results.

\begin{tabular}{|c|c|c|c|c|c|}
\hline$H(\mathrm{~m})$ & $N$ & $q(\mathrm{~W})$ & $\Delta T\left({ }^{\circ} \mathrm{C}\right)$ & $R\left({ }^{\circ} \mathrm{C} / \mathrm{W}\right)$ & $N u_{L}$ \\
\hline \multirow{5}{*}{0.01} & \multirow{5}{*}{9} & 0.53 & $10.3 \pm 0.8$ & $19.53 \pm 1.56$ & $7.02 \pm 0.56$ \\
\hline & & 1.35 & $18.7 \pm 0.6$ & $13.83 \pm 0.43$ & $9.91 \pm 0.31$ \\
\hline & & 2.39 & $29.5 \pm 0.7$ & $12.35 \pm 0.28$ & $11.1 \pm 0.25$ \\
\hline & & 3.3 & $39.2 \pm 1.1$ & $11.87 \pm 0.33$ & $11.56 \pm 0.33$ \\
\hline & & 4.55 & $49.4 \pm 0.5$ & $10.86 \pm 0.11$ & $12.63 \pm 0.13$ \\
\hline \multirow{5}{*}{0.01} & \multirow{5}{*}{12} & 0.64 & $10.4 \pm 0.6$ & $16.37 \pm 0.93$ & $7.55 \pm 0.43$ \\
\hline & & 1.46 & $19.8 \pm 0.7$ & $13.55 \pm 0.48$ & $9.12 \pm 0.32$ \\
\hline & & 2.42 & $30.7 \pm 0.7$ & $12.72 \pm 0.31$ & $9.72 \pm 0.23$ \\
\hline & & 3.41 & $40.8 \pm 0.9$ & $11.98 \pm 0.27$ & $10.32 \pm 0.24$ \\
\hline & & 4.53 & $50.4 \pm 0.6$ & $11.12 \pm 0.12$ & $11.12 \pm 0.12$ \\
\hline \multirow{5}{*}{0.01} & \multirow{5}{*}{18} & 0.69 & $10.3 \pm 0.5$ & $14.89 \pm 0.73$ & $6.94 \pm 0.34$ \\
\hline & & 1.57 & $20.5 \pm 0.5$ & $13.05 \pm 0.35$ & $7.91 \pm 0.21$ \\
\hline & & 2.65 & $29.8 \pm 0.6$ & $11.23 \pm 0.22$ & $9.2 \pm 0.18$ \\
\hline & & 4.05 & $40.5 \pm 0.8$ & $10.01 \pm 0.19$ & $10.32 \pm 0.19$ \\
\hline & & 5.46 & $50 \pm 1.1$ & $9.16 \pm 0.2$ & $11.27 \pm 0.24$ \\
\hline \multirow{5}{*}{0.01} & \multirow{5}{*}{36} & 0.73 & $10.2 \pm 0.5$ & $13.86 \pm 0.73$ & $4.99 \pm 0.26$ \\
\hline & & 1.73 & $20.1 \pm 0.5$ & $11.65 \pm 0.3$ & $5.93 \pm 0.15$ \\
\hline & & 3.02 & $29.8 \pm 0.6$ & $9.88 \pm 0.21$ & $7 \pm 0.15$ \\
\hline & & 4.59 & $40.2 \pm 0.5$ & $8.76 \pm 0.11$ & $7.89 \pm 0.1$ \\
\hline & & 6.32 & $50.7 \pm 0.5$ & $8.02 \pm 0.08$ & $8.62 \pm 0.09$ \\
\hline \multirow{5}{*}{0.01} & \multirow{5}{*}{72} & 0.82 & $10.1 \pm 0.6$ & $12.39 \pm 0.69$ & $3.36 \pm 0.19$ \\
\hline & & 1.84 & $20.2 \pm 0.6$ & $10.97 \pm 0.32$ & $3.79 \pm 0.11$ \\
\hline & & 2.9 & $29.5 \pm 0.8$ & $10.18 \pm 0.29$ & $4.09 \pm 0.12$ \\
\hline & & 4.32 & $40.3 \pm 0.6$ & $9.32 \pm 0.13$ & $4.46 \pm 0.06$ \\
\hline & & 6.01 & $50.8 \pm 0.6$ & $8.45 \pm 0.09$ & $4.93 \pm 0.06$ \\
\hline \multirow{5}{*}{0.02} & \multirow{5}{*}{9} & 0.95 & $10.4 \pm 0.5$ & $10.99 \pm 0.54$ & $9.39 \pm 0.46$ \\
\hline & & 2.25 & $20.3 \pm 0.5$ & $9.03 \pm 0.23$ & $11.42 \pm 0.29$ \\
\hline & & 3.64 & $29.7 \pm 0.5$ & $8.16 \pm 0.15$ & $12.65 \pm 0.23$ \\
\hline & & 5.04 & $40.4 \pm 0.8$ & $8.03 \pm 0.15$ & $12.85 \pm 0.24$ \\
\hline & & 6.96 & $49.7 \pm 0.5$ & $7.14 \pm 0.08$ & $14.45 \pm 0.15$ \\
\hline \multirow{5}{*}{0.02} & \multirow{5}{*}{12} & 1.32 & $10.1 \pm 0.6$ & $7.68 \pm 0.42$ & $11.53 \pm 0.63$ \\
\hline & & 2.92 & $19.5 \pm 0.6$ & $6.68 \pm 0.21$ & $13.26 \pm 0.42$ \\
\hline & & 4.55 & $29.9 \pm 0.6$ & $6.58 \pm 0.13$ & $13.46 \pm 0.26$ \\
\hline & & 5.93 & $40.1 \pm 0.6$ & $6.77 \pm 0.11$ & $13.08 \pm 0.21$ \\
\hline & & 7.86 & $50.9 \pm 1$ & $6.47 \pm 0.12$ & $13.69 \pm 0.26$ \\
\hline \multirow{5}{*}{0.02} & \multirow{5}{*}{18} & 1.24 & $10.4 \pm 0.6$ & $8.42 \pm 0.51$ & $8.2 \pm 0.49$ \\
\hline & & 2.95 & $20.5 \pm 0.6$ & $6.94 \pm 0.19$ & $9.95 \pm 0.28$ \\
\hline & & 4.83 & $30.5 \pm 0.7$ & $6.32 \pm 0.14$ & $10.93 \pm 0.24$ \\
\hline & & 7.35 & $40.5 \pm 0.6$ & $5.51 \pm 0.08$ & $12.53 \pm 0.18$ \\
\hline & & 9.47 & $50.7 \pm 0.6$ & $5.36 \pm 0.06$ & $12.88 \pm 0.15$ \\
\hline \multirow{5}{*}{0.02} & \multirow{5}{*}{36} & 1.6 & $9.6 \pm 0.6$ & $6.03 \pm 0.35$ & $6.9 \pm 0.4$ \\
\hline & & 3.63 & $19.9 \pm 0.6$ & $5.47 \pm 0.16$ & $7.59 \pm 0.22$ \\
\hline & & 5.92 & $30 \pm 0.7$ & $5.07 \pm 0.12$ & $8.2 \pm 0.19$ \\
\hline & & 8.75 & $39.5 \pm 0.5$ & $4.52 \pm 0.06$ & $9.19 \pm 0.12$ \\
\hline & & 12.03 & $50.7 \pm 0.6$ & $4.21 \pm 0.05$ & $9.87 \pm 0.11$ \\
\hline & & 1.58 & $10 \pm 0.8$ & $6.34 \pm 0.48$ & $3.65 \pm 0.27$ \\
\hline & & 3.13 & $19.9 \pm 0.8$ & $6.38 \pm 0.25$ & $3.63 \pm 0.14$ \\
\hline 0.02 & 72 & 5.07 & $29.6 \pm 0.6$ & $5.82 \pm 0.11$ & $3.97 \pm 0.08$ \\
\hline & & 7.37 & $39.8 \pm 0.6$ & $5.4 \pm 0.08$ & $4.29 \pm 0.06$ \\
\hline & & 9.9 & $50.1 \pm 0.6$ & $5.06 \pm 0.06$ & $4.58 \pm 0.06$ \\
\hline & & 1.32 & $10.2 \pm 0.5$ & $7.71 \pm 0.38$ & $10.72 \pm 0.53$ \\
\hline & & 2.96 & $21 \pm 0.5$ & $7.08 \pm 0.18$ & $11.67 \pm 0.3$ \\
\hline 0.03 & 9 & 4.39 & $30.1 \pm 0.5$ & $6.86 \pm 0.13$ & $12.05 \pm 0.22$ \\
\hline & & 6.49 & $41.3 \pm 0.7$ & $6.36 \pm 0.11$ & $13 \pm 0.22$ \\
\hline & & 8.29 & $50.9 \pm 0.5$ & $6.14 \pm 0.06$ & $13.45 \pm 0.14$ \\
\hline
\end{tabular}


Table 3. Cont.

\begin{tabular}{|c|c|c|c|c|c|}
\hline$H(\mathrm{~m})$ & $N$ & $q(\mathrm{~W})$ & $\Delta T\left({ }^{\circ} \mathrm{C}\right)$ & $R\left({ }^{\circ} \mathrm{C} / \mathrm{W}\right)$ & $N u_{L}$ \\
\hline \multirow{5}{*}{0.03} & \multirow{5}{*}{12} & 1.46 & $9.7 \pm 0.5$ & $6.63 \pm 0.36$ & $10.39 \pm 0.56$ \\
\hline & & 3.17 & $20.1 \pm 0.6$ & $6.33 \pm 0.19$ & $10.89 \pm 0.33$ \\
\hline & & 4.93 & $29.7 \pm 0.7$ & $6.03 \pm 0.15$ & $11.43 \pm 0.28$ \\
\hline & & 7.21 & $40 \pm 0.5$ & $5.55 \pm 0.07$ & $12.42 \pm 0.16$ \\
\hline & & 9.21 & $49.4 \pm 0.5$ & $5.37 \pm 0.06$ & $12.85 \pm 0.14$ \\
\hline \multirow{5}{*}{0.03} & \multirow{5}{*}{18} & 1.83 & $10.4 \pm 0.5$ & $5.66 \pm 0.27$ & $9.16 \pm 0.44$ \\
\hline & & 3.99 & $19.9 \pm 0.5$ & $4.99 \pm 0.13$ & $10.39 \pm 0.26$ \\
\hline & & 6.36 & $29.9 \pm 0.5$ & $4.7 \pm 0.08$ & $11.02 \pm 0.2$ \\
\hline & & 9.15 & $40.2 \pm 0.5$ & $4.39 \pm 0.06$ & $11.81 \pm 0.15$ \\
\hline & & 11.97 & $50.1 \pm 0.5$ & $4.18 \pm 0.04$ & $12.38 \pm 0.13$ \\
\hline \multirow{5}{*}{0.03} & \multirow{5}{*}{36} & 2.03 & $10.3 \pm 0.5$ & $5.09 \pm 0.26$ & $5.83 \pm 0.3$ \\
\hline & & 4.68 & $19.9 \pm 0.5$ & $4.26 \pm 0.11$ & $6.97 \pm 0.18$ \\
\hline & & 7.83 & $29.8 \pm 0.5$ & $3.8 \pm 0.07$ & $7.81 \pm 0.14$ \\
\hline & & 11.49 & $40.1 \pm 0.5$ & $3.49 \pm 0.05$ & $8.51 \pm 0.11$ \\
\hline & & 15.28 & $50.2 \pm 0.5$ & $3.28 \pm 0.03$ & $9.04 \pm 0.09$ \\
\hline \multirow{5}{*}{0.03} & \multirow{5}{*}{72} & 1.85 & $10.2 \pm 0.5$ & $5.51 \pm 0.29$ & $2.91 \pm 0.15$ \\
\hline & & 3.58 & $20.1 \pm 0.8$ & $5.63 \pm 0.21$ & $2.84 \pm 0.11$ \\
\hline & & 6.22 & $30.2 \pm 0.6$ & $4.85 \pm 0.09$ & $3.3 \pm 0.06$ \\
\hline & & 8.97 & $40.3 \pm 0.7$ & $4.5 \pm 0.08$ & $3.56 \pm 0.06$ \\
\hline & & 11.89 & $50.5 \pm 0.6$ & $4.24 \pm 0.05$ & $3.77 \pm 0.04$ \\
\hline
\end{tabular}

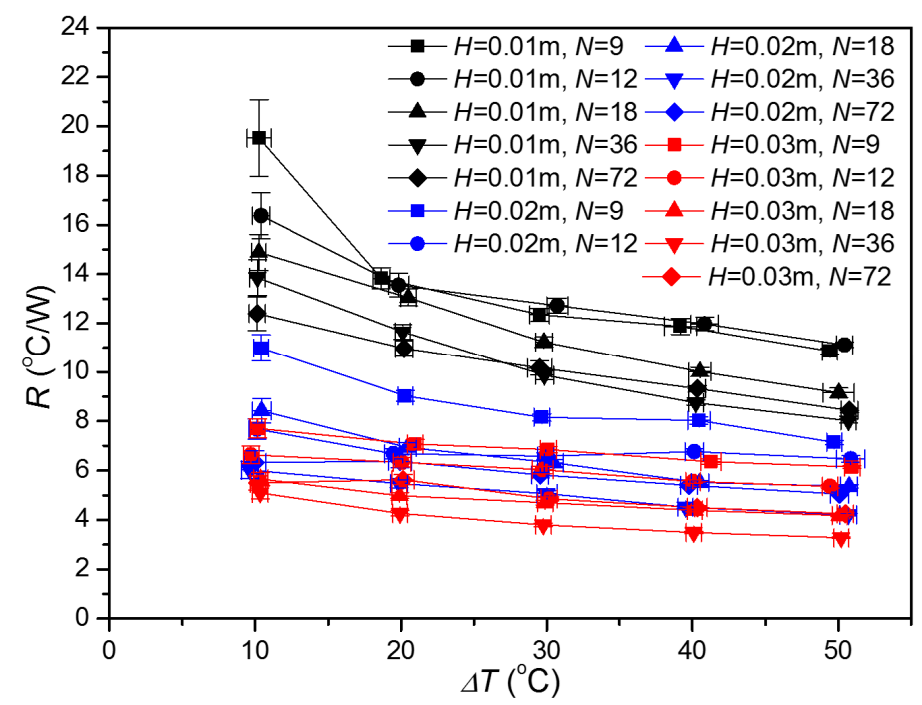

Figure 6. Thermal resistances of inverted-triangular-finned tubes.

In the present study, the Nusselt number correlation for vertical tubes with inverted triangular fins that best predicts the measurement results is proposed on the basis of analysis of previous studies. Harahap and McManus [14] investigated natural convection from a plate finned horizontal surface. They non-dimensionalized the continuity, momentum, and energy equations and found that the Nusselt number depends on $R a_{H} A_{c} / L H, L / H$, and $S_{\text {ave }} / H$. $R a_{H} A_{c} / L H$ is related to the dimensionless fluid velocity. $L / H$ and $S_{\text {ave }} / H$ denote the dimensionless fin length and dimensionless fin-by-fin spacing, respectively. Further, $R a_{H}, A_{c}$, and $S_{\text {ave }}$ denote the Rayleigh number, cross-sectional area of the buoyancy-induced vertical flow, and average fin-by-fin spacing, respectively. Flow and temperature fields around vertical tubes with inverted triangular fins also satisfy their governing equations, and their analysis is also suitable for developing the Nusselt number correlation for vertical tubes with inverted triangular fins. Therefore, in the present study, the Nusselt number is assumed to depend on 
$R a_{H} A_{c} / L H, S_{a v e} / H$, and $L / H$. In the case of the vertical tube with inverted triangular fins, $R a_{H}, A_{c}$, and $S_{\text {ave }}$ are, respectively, expressed as:

$$
\begin{gathered}
R a_{H}=g \beta_{f} \Delta T H^{3} /\left(v_{f} \alpha_{f}\right), \\
A_{c}=\pi(H+D / 2)^{2}-\pi(D / 2)^{2}, \\
s_{\text {ave }}=\pi(H+D) / N-t .
\end{gathered}
$$

and the Nusselt number is expressed as:

$$
N u_{L}=f\left(R a_{H} A_{c} /(L H), s_{a v e} / H, L / H\right) .
$$

Next, a proper function for the Nusselt number correlation (Equation (10)) is found by considering the characteristics of the Nusselt number for finned tubes under natural convection. The Nusselt number has the following characteristics:

(a) When the fin-by-fin spacing is large enough, the thermal boundary layer growing on a fin is unaffected by the thermal boundary layers growing on nearby fins. Therefore, in this case, the Nusselt number does not depend on the fin-by-fin spacing $S_{\text {ave }}$.

(b) When the fin-by-fin spacing is small, the thermal boundary layer on a fin merges with thermal boundary layers growing on nearby fins. The amount of overlap increases as the fin-by-fin spacing decreases. As a result, as the fin-by-fin spacing decreases, the Nusselt number decreases monotonically.

(c) In the case of natural convection, buoyancy caused by the temperature difference drives the fluid flow. As a result, the Nusselt number increases monotonically as the temperature difference increases.

Various functions that possess these characteristics are examined using the least-squares fitting method in order to determine whether they can predict the experimental results well. Finally, it is found that the measurement results are predicted best when the functional form is:

$$
N u_{L}=C_{1}\left(R a_{H} A_{c} /(L H)\right)^{C_{2}}\left(1+C_{3}\left(s_{\text {ave }} / H\right)^{-C_{4}}\right)^{-1}(L / H)^{C_{5}},
$$

when the corresponding empirical coefficients are:

$$
C_{1}=0.801, C_{2}=0.213, C_{3}=0.146, C_{4}=1.33, C_{5}=0.376 \text {. }
$$

In other words, the Nusselt number correlation for the inverted-triangular-finned tube is:

$$
N u_{L}=0.801\left(R a_{H} A_{c} /(L H)\right)^{0.213}\left(1+0.146\left(s_{\text {ave }} / H\right)^{-1.33}\right)^{-1}(L / H)^{0.376} .
$$

The suggested Nusselt number correlations has the following characteristics:

(a) The Nusselt number increases as $R a_{H} A_{c} / L H$ increases. This is because buoyancy caused by the temperature difference drives the fluid flow in the case of natural convection, and the Nusselt number increases monotonically as the temperature difference increases.

(b) The Nusselt number does not depend on $S_{\text {ave }} / H$ when $\left(S_{\text {ave }} / H\right)>(1 / 0.146)^{(-1 / 1.33)}=0.235$. It is because the thermal boundary layer growing on a fin is unaffected by the thermal boundary layers growing on nearby fins when the fin-by-fin spacing $S_{\text {ave }}$ is large enough.

(c) The Nusselt number decreases monotonically as $S_{\text {ave }} / H$ decreases when $\left(S_{\text {ave }} / H\right)<0.235$. It is because the thermal boundary layer on a fin merges with thermal boundary layers growing on nearby fins when the fin-by-fin spacing $S_{\text {ave }}$ is small, and the amount of overlap increases as the fin-by-fin spacing decreases. 
(d) The last term of the correlation $(L / H)^{0.376}$ is related to the length dependence of the heat transfer coefficient. As a result, the heat transfer coefficient $h$ is proportional to $L^{0.376-0.213-1}=L^{-0.837}$, and the heat transfer coefficient decreases as the length increases. This is because the local thermal boundary layer thickness increases as the distance from the bottom side of the finned tube increases, and the average thermal boundary layer thickness decreases as the length increases.

Figure 7 shows a comparison of the Nusselt numbers obtained using the proposed correlation with those obtained from the experimental data. This figure shows that the experimental results are predicted well by the proposed correlation, within a $\pm 15 \%$ error. The proposed correlation is applicable to the conditions of Rayleigh numbers of 1000-125,000, fin height to fin length ratios of $0.2-0.6$, and fin numbers of 9-72, within which ranges the thermal resistances were measured and the Nusselt numbers were calculated.

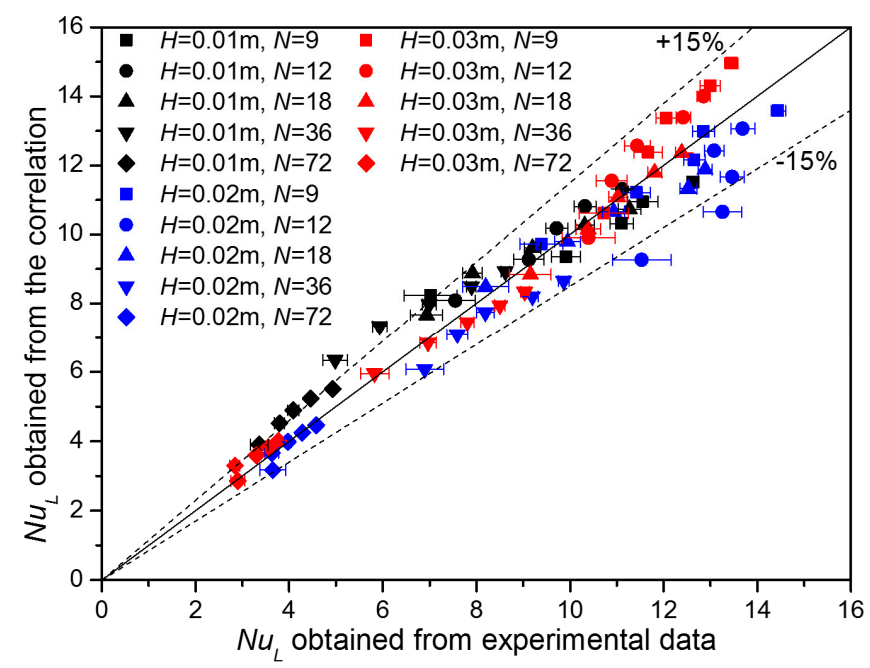

Figure 7. Comparison of Nusselt numbers obtained from experimental data with those obtained using proposed correlation.

Figures 8 and 9 show the effects of the fin number and fin height, respectively, on the thermal resistances. In Figures 8 and 9, thermal resistances obtained from both the experimental data and the proposed correlation are shown, and they are found to match well, within a $\pm 15 \%$ error. As shown in Figure 8, the thermal resistance decreases as the fin number $N$ increases when $9<N<36$. However, the thermal resistance increases when $N>36$. As a result, there exists an optimal fin number $(N=36)$ at which the thermal resistance is minimized. To explain this trend, the effects of the fin number on the effective surface area, heat transfer coefficient, and thermal resistance are determined, as shown in Figure 10, by using the proposed correlation. Figure 10 shows that the finned tube with a larger number of fins has a larger effective surface area $A_{\text {eff }}$ because of the larger surface area of fins. However, the heat transfer coefficient $h$ for the finned tube with a larger number of fins is smaller because the overlap of the boundary layer is greater at a small fin-by-fin spacing. As a result, there exists an optimal fin number at which the thermal resistance is minimized. In Figure 9, the thermal resistance decreases as the fin height $H$ increases. As shown in Figure 11, this is because the finned tube with a greater fin height has a larger effective surface area but the heat transfer coefficient does not strongly depend on the fin height. In addition, the thermal resistances of the tube without fins are calculated based on [10], and are shown in Figure 9. The thermal resistance of the tube without fins is several times greater than that of the finned tube. 


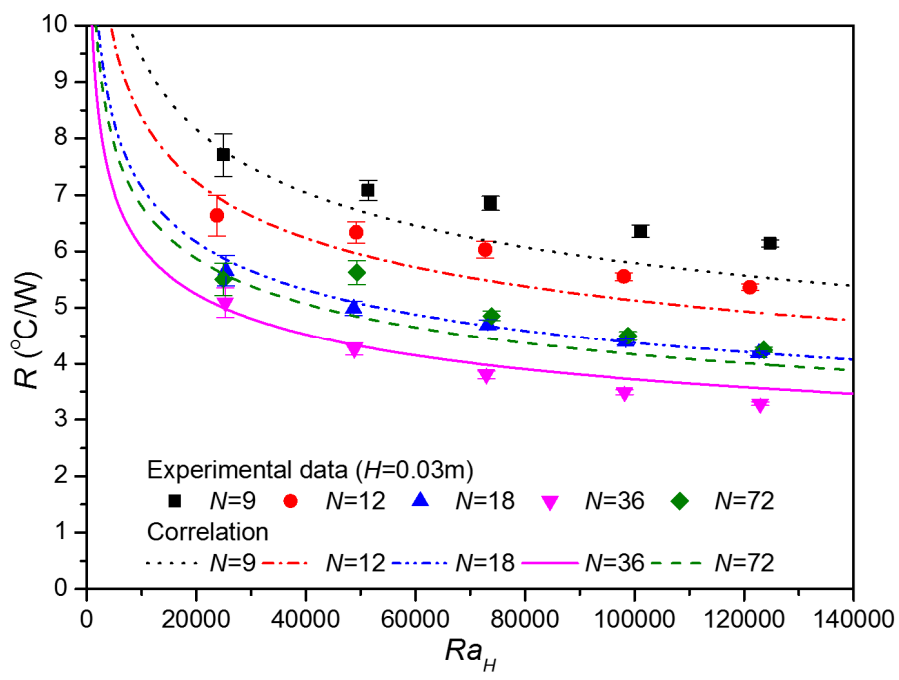

Figure 8. Effect of fin number on thermal resistance.

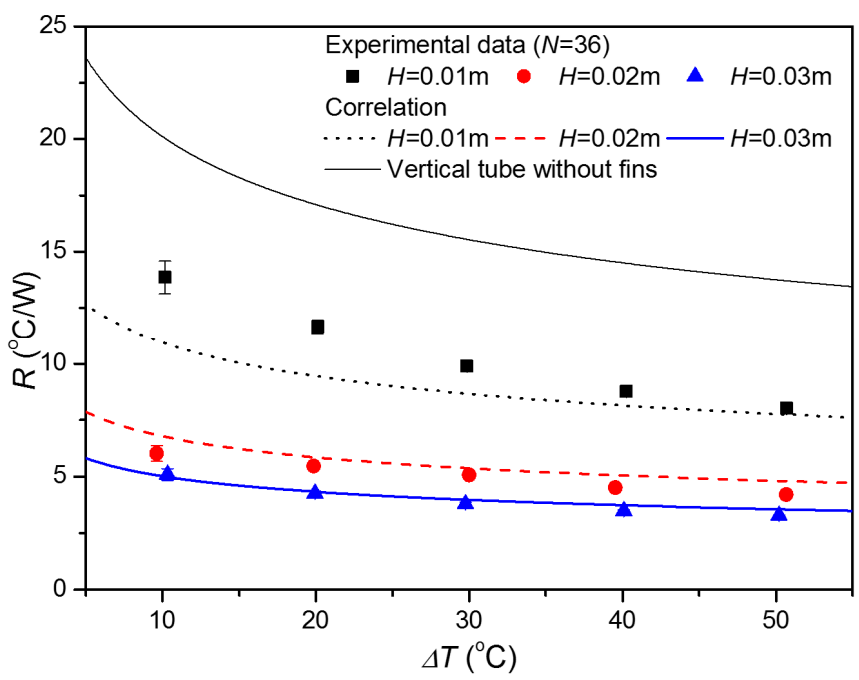

Figure 9. Effect of fin height on thermal resistance.

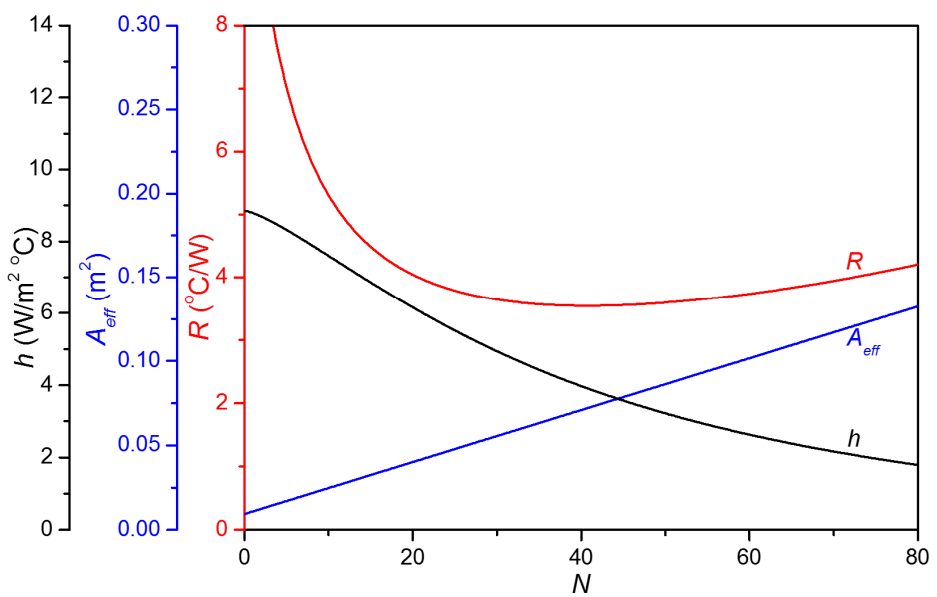

Figure 10. Effects of fin number on effective surface area, heat transfer coefficient, and thermal resistance. 


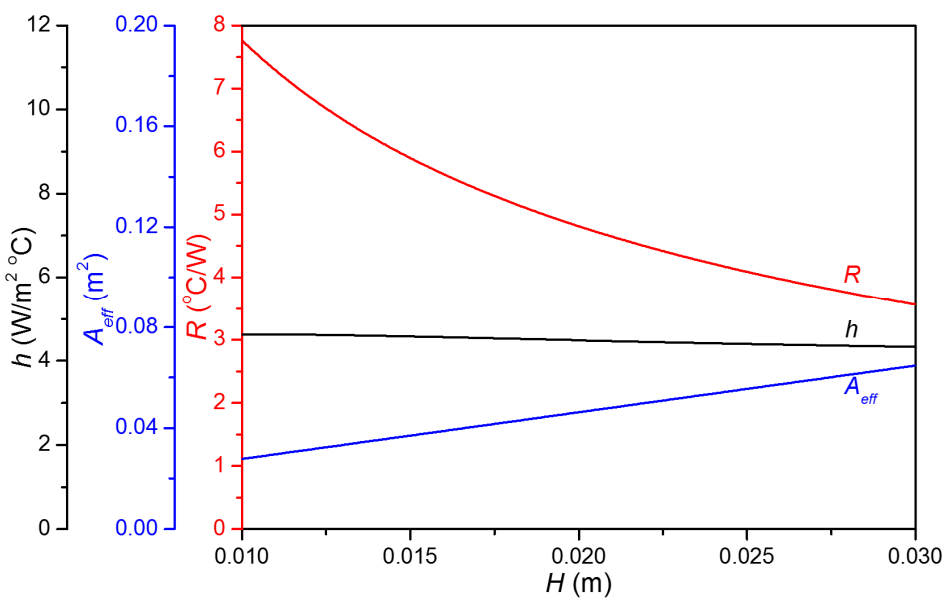

Figure 11. Effects of fin height on effective surface area, heat transfer coefficient, and thermal resistance.

Next, the thermal resistances of the inverted-triangular-finned tube under free convection were obtained using the proposed Nusselt number correlation with the properties and constraints listed in Table 4; the contour map showing the thermal resistances for various fin thicknesses and fin numbers is depicted in Figure 12. The figure shows that there exist optimal values of the fin thickness and fin number at which the thermal resistance is minimized. This is because the effective surface area decreases (Figure 13a) but the heat transfer coefficient increases (Figure 13b) with decreases in the fin number and fin thickness. The proposed Nusselt number correlation enables a search for the optimal dimensions of the finned tube. Therefore, the proposed correlation has potential to be used in the designing of triangular-finned tubes of various cooling devices of energy conversion systems including lighting systems, power plants, air conditioning systems, refrigeration systems, and transportation systems.

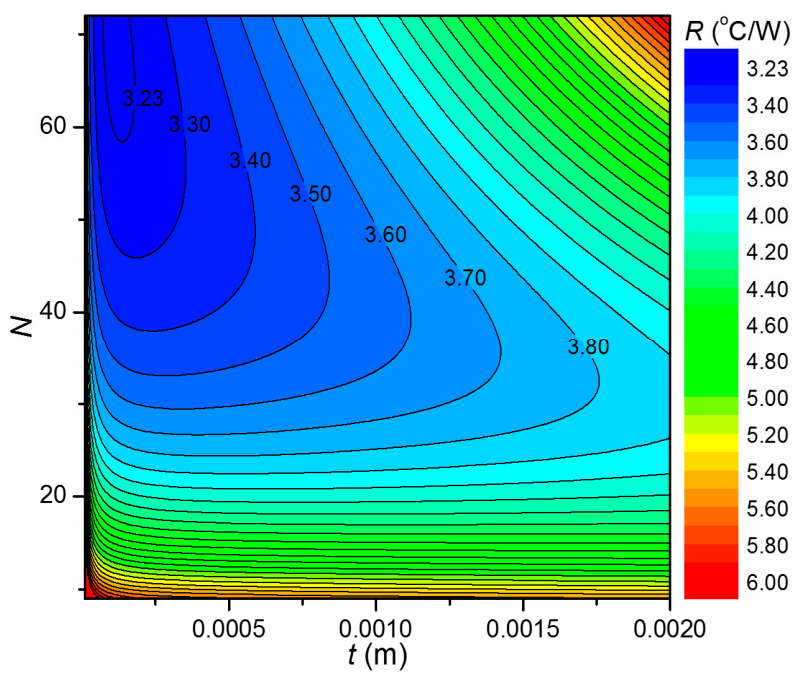

Figure 12. Contour map of thermal resistance. 


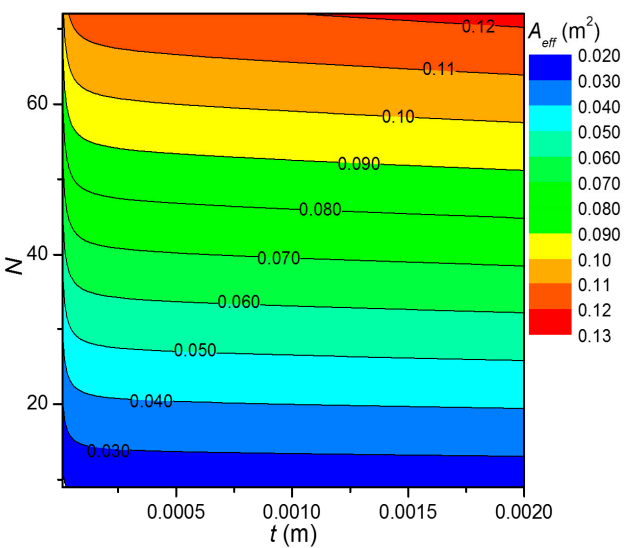

(a)

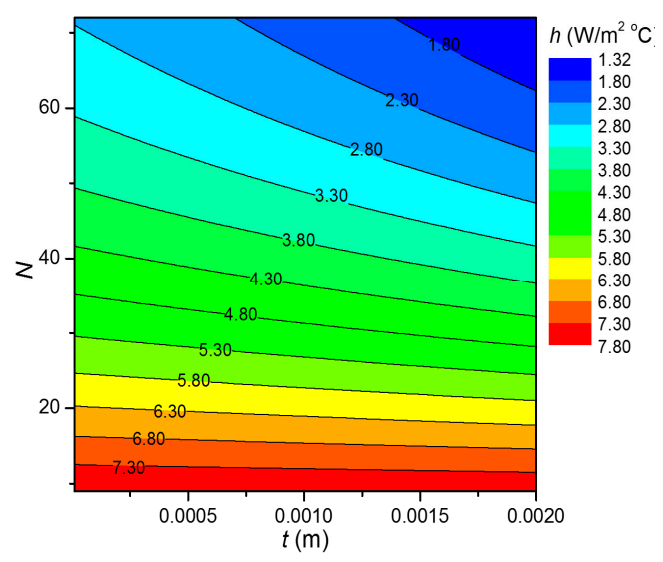

(b)

Figure 13. Contour maps of (a) effective surface area and (b) heat transfer coefficient.

Table 4. Properties and constraints for contour maps.

\begin{tabular}{cccc}
\hline \multicolumn{2}{c}{ Properties } & \multicolumn{2}{c}{ Constraints } \\
\hline$\alpha_{f}$ & $2.23 \times 10^{-5} \mathrm{~m}^{2} / \mathrm{s}$ & $\Delta T$ & $50{ }^{\circ} \mathrm{C}$ \\
$\beta_{f}$ & $0.0033 / \mathrm{K}$ & $L$ & $50 \mathrm{~mm}$ \\
$v_{f}$ & $1.6 \times 10^{-5} \mathrm{~m}^{2} / \mathrm{s}$ & $D$ & $60 \mathrm{~mm}$ \\
$k_{f}$ & $0.026 \mathrm{~W} / \mathrm{m} \cdot{ }^{\circ} \mathrm{C}$ & $H$ & $30 \mathrm{~mm}$ \\
$k_{s}$ & $220 \mathrm{~W} / \mathrm{m} \cdot{ }^{\circ} \mathrm{C}$ & $T$ & $0.01-2 \mathrm{~mm}$ \\
- & - & $N$ & $9-72$ \\
\hline
\end{tabular}

\section{Conclusions}

Vertical tubes with inverted triangular fins under natural convection are investigated experimentally. The thermal resistances of these tubes are measured for various heat inputs, fin heights, and fin numbers. A Nusselt number correlation that best predicts the measured thermal resistances is proposed. The proposed correlation is applicable under the following conditions: Rayleigh numbers of 1000-125,000, fin height to fin length ratios of 0.2-0.6, and fin numbers of 9-72. Finally, a contour map of the thermal resistances calculated from the proposed correlation for various fin thicknesses and fin numbers is presented. The contour map shows that there exist optimal values of the fin thickness and fin number at which the thermal resistance of the inverted-triangular-finned tube is minimized. Therefore, the proposed correlation enables a search for the optimal dimensions of the finned tube and has potential to be used in the designing of inverted-triangular-finned tubes of various cooling devices.

Acknowledgments: This research was supported by Nano-Material Technology Development Program through the National Research Foundation of Korea (NRF) funded by the Ministry of Science, ICT, and Future Planning (NRF-2011-0030285).

Author Contributions: The experiments were conducted by Byeong Dong Kang; the experimental results were analyzed by Dong-Kwon Kim and Hyun Jung Kim; and the paper was written by Dong-Kwon Kim.

Conflicts of Interest: The authors declare no conflict of interest.

\section{References}

1. Pimputkar, S.; Speck, J.S.; DenBaars, S.P.; Nakamura, S. Prospects for LED Lighting. Nat. Photonics 2009, 3, 180-182. [CrossRef]

2. Lasance, C.J.M.; Poppe, A. (Eds.) Thermal Management for LED Applications; Springer: New York, NY, USA, 2014.

3. Liu, J.; Tam, W.S.; Wong, H.; Filip, V. Temperature-dependent Light-Emitting Characteristics of InGaN/GaN Diodes. Microelectron. Reliab. 2009, 49, 38-41. [CrossRef]

4. Chang, M.-H.; Das, D.; Varde, P.V.; Pecht, M. Light Emitting Diodes Reliability Review. Microelectron. Reliab. 2012, 52, 762-782. [CrossRef] 
5. Luo, X.; Liu, S. A Microjet Array Cooling System for Thermal Management of High-brightness LEDs. IEEE Trans. Adv. Packag. 2007, 30, 475-484. [CrossRef]

6. Park, J.; Shin, M.; Lee, C.C. Measurement of Temperature Profiles on Visible Light-Emitting Diodes by Use of a Nematic Liquid Crystal and an Infrared Laser. Opt. Lett. 2004, 29, 2656-2658. [CrossRef] [PubMed]

7. Narendran, N.; Gu, Y. Life of LED-based White Light Sources. J. Disp. Technol. 2005, 1, 167-171. [CrossRef]

8. Incropera, F.P. Convection Heat Transfer in Electronic Equipment Cooling. J. Heat Transf. 1988, 110, $1097-1111$. [CrossRef]

9. Nakayama, W. Thermal Management of Electronic Equipment: A Review of Technology and Research Topics. Appl. Mech. Rev. 1986, 39, 1847-1868. [CrossRef]

10. Churchill, S.W.; Chu, H.H. Correlating Equations for Laminar and Turbulent Free Convection from a Vertical Plate. Int. J. Heat Mass Transf. 1975, 18, 1323-1329. [CrossRef]

11. Goldstein, R.J.; Sparrow, E.M.; Jones, D.C. Natural Convection Mass Transfer Adjacent to Horizontal Plates. Int. J. Heat Mass Transf. 1973, 16, 1025-1035. [CrossRef]

12. Minkowycz, W.J.; Sparrow, E.M. Local Nonsimilar Solutions for Natural Convection on a Vertical Cylinder. J. Heat Transf. 1974, 96, 178-183. [CrossRef]

13. Churchill, S.W.; Chu, H.H. Correlating Equations for Laminar and Turbulent Free Convection from a Horizontal Cylinder. Int. J. Heat Mass Transf. 1975, 18, 1049-1053. [CrossRef]

14. Harahap, F.; McManus, H.N. Natural Convection Heat Transfer from Horizontal Rectangular Fin Arrays. J. Heat Transf. 1967, 89, 32-38. [CrossRef]

15. Welling, J.R.; Wooldridge, C.B. Free Convection Heat Transfer Coefficients from Rectangular Vertical Fins. J. Heat Transf. 1965, 87, 439-444. [CrossRef]

16. Sparrow, E.M.; Bahrami, P.A. Experiments on Natural Convection Heat Transfer on the Fins of a Finned Horizontal Tube. Int. J. Heat Mass Transf. 1980, 23, 1555-1560. [CrossRef]

17. Yildiz, Ş.; Yüncü, H. An Experimental Investigation on Performance of Annular Fins on a Horizontal Cylinder in Free Convection Heat Transfer. Heat Mass Transf. 2004, 40, 239-251. [CrossRef]

18. Yu, S.-H.; Lee, K.-S.; Yook, S.-J. Natural Convection around a Radial Heat Sink. Int. J. Heat Mass Transf. 2010, 53, 2935-2938. [CrossRef]

19. Costa, V.A.F.; Lopes, A.M.G. Improved Radial Heat Sink for LED Lamp Cooling. Appl. Therm. Eng. 2014, 70, 131-138. [CrossRef]

20. Yu, S.-H.; Lee, K.-S.; Yook, S.-J. Optimum Design of a Radial Heat Sink under Natural Convection. Int. J. Heat Mass Transf. 2011, 54, 2499-2505. [CrossRef]

21. Jang, D.; Yu, S.-H.; Lee, K.-S. Multidisciplinary Optimization of a Pin-fin Radial Heat Sink for LED Lighting Applications. Int. J. Heat Mass Transf. 2012, 55, 515-521. [CrossRef]

22. Jang, D.; Yook, S.-J.; Lee, K.-S. Optimum Design of a Radial Heat Sink with a Fin-height Profile for High-power LED Lighting Applications. Appl. Energy 2014, 116, 260-268. [CrossRef]

23. Park, S.-J.; Jang, D.; Yook, S.-J.; Lee, K.-S. Optimization of a Staggered Pin-fin for a Radial Heat Sink under Free Convection. Int. J. Heat Mass Transf. 2015, 87, 184-188. [CrossRef]

24. Park, S.-J.; Jang, D.; Lee, K.-S. Thermal Performance Improvement of a Radial Heat Sink with a Hollow Cylinder for LED Downlight Applications. Int. J. Heat Mass Transf. 2015, 89, 1184-1189. [CrossRef]

25. Park, S.-J.; Lee, K.-S. Orientation Effect of a Radial Heat Sink with a Chimney for LED Downlights. Int. J. Heat Mass Transf. 2017, 110, 416-421. [CrossRef]

26. An, B.H.; Kim, H.J.; Kim, D.-K. Nusselt Number Correlation for Natural Convection from Vertical Cylinders with Vertically Oriented Plate Fins. Exp. Therm. Fluid Sci. 2012, 41, 59-66. [CrossRef]

27. Park, K.T.; Kim, H.J.; Kim, D.-K. Experimental Study of Natural Convection from Vertical Cylinders with Branched Fins. Exp. Therm. Fluid Sci. 2014, 54, 29-37. [CrossRef]

28. Jang, D.; Kim, D.R.; Lee, K.-S. Correlation of Cross-cut Cylindrical Heat Sink to Improve the Orientation Effect of LED Light Bulbs. Int. J. Heat Mass Transf. 2015, 84, 821-826. [CrossRef]

29. Lee, M.; Kim, H.J.; Kim, D.-K. Nusselt Number Correlation for Natural Convection from Vertical Cylinders with Triangular Fins. Appl. Therm. Eng. 2016, 93, 1238-1247. [CrossRef]

(C) 2017 by the authors. Licensee MDPI, Basel, Switzerland. This article is an open access article distributed under the terms and conditions of the Creative Commons Attribution (CC BY) license (http:/ / creativecommons.org/licenses/by/4.0/). 